\title{
Decongestive Physiotherapy for the Treatment of Lymphedema
}

\section{Lisa M. Hodge}

Department of Molecular Biology, Osteopathic Research Center, University of North Texas Health Science Center Fort Worth, Texas, USA

In the United States, approximately one in four women diagnosed with breast cancer will develop secondary arm lymphedema after axillary dissection. These patients experience significant functional limb impairment, psychological morbidity and a reduction on their perceived quality of life [1]. The efficacy of pharmaceutical interventions for lymph edema is uncertain; therefore, most therapies prescribed are non-pharmaceutical [2]. While the mechanisms are poorly understood, decongestive physiotherapy (consisting of skin care, manual lymph drainage, lymphatic/pneumatic pumps, exercise and compression wrapping) is effective for the treatment of lymphedema [2]. In support, passive limb movement, [3] exercise, [4-5] and manual lymph pumping [6-7] have been shown to enhance lymphatic flow in animals. Therefore, it is likely that by enhancing lymph flow, these therapies aid in the release and redistribution of lymph pools, which may reduce lymph edema.

While non-pharmaceutical treatments such as decongestive physiotherapy have been shown to relieve the symptoms of secondary lymphedema, [1-2] many therapists are reluctant to perform these treatments on patients with cancer, for fear of promoting metastasis through the lymphatic system [8]. This concern is validated by early studies demonstrating that massage certain primary tumors promotes metastasis in mice; [9-11] however, the mechanism responsible for this pathogenesis still warrants study.

In conclusion, there is no consensus that manual physiotherapies designed to reduce lymph edema promote metastasis. Many clinicians agree the benefit to patients suffering with lymphedema secondary to breast cancer far outweighs the potential risk of adverse events. Nonetheless, clinicians remain divided on their approach to the treatment of lymphedema in these patients, substantiating the need for evidence-based research to identify the potential risks of decongestive physiotherapy in patients with cancer.

\section{References}

1. Rockson SD (2001) Lymphedema Am J Med 110: 288-295.

2. Erickson S, Pearson ML, Ganz PA, Adams J, Kahn K (2001) Arm Edema in Breast Cancer Patients. Journal of the National Cancer Institute 93: 96-111.

3. Schad H, Brechtelsbauer $\mathrm{H}$ (1977) Thoracic duct lymph flow and composition in conscious dogs and the influence of anaesthesia and passive limb movement. Pflugers Arch 371: 25-31.

4. Knott EM, Tune JD, Stoll ST, Downey HF (2005) Increased lymphatic flow in the thoracic duct during manipulative intervention. J Am Osteopath Assoc 105: 447-456.

5. Downey HF, Durgam P, Williams AG, Rajmane A, King HH, et al. (2008) Lymph flow in the thoracic duct of conscious dogs during lymphatic pump treatment exercise, and expansion of extracellular fluid volume. Lymphat Res Biol 6: 3-13.

6. Hodge LM, Bearden MK, Schander A, Huff JB, Williams A, et al. (2010) Abdominal lymphatic pump treatment mobilizes leukocytes from the gastrointestinal associated lymphoid tissue into lymph. Lymphat Res Biol 8: 103-110.

7. Huff JB, Schander A, Downey HF, Hodge LM (2010) Lymphatic pump treatment augments lymphatic flux of lymphocytes in rats. Lymphat Res Biol 8: 183-187.

8. Pinell XA, Kirkpatrick S, Hawkins K, Mondry T, Johnstone P (2008) Manipulative therapy of secondary lymphedema in the presence of locoregional tumors. Cancer 112: 950-954

9. Weiss L, Mayhew E, Glaves Rapp D, Holmes JC (1982) Metastatic Inefficieny in Mice Bearing B16 Melanomas. Br J Cancer 45: 44-53.

10. Hoover HC, Ketcham AS (1975) Techniques for inhibiting tumor metastases Cancer 35: 5-14.

11. Tyzzer EE (1919) Factors in the production and growth of tumor metastases. J Med Res 28: 309-332.
*Corresponding author: : Lisa M. Hodge, The University of North Texas Health Science Center, 3500 Camp Bowie Boulevard, Fort Worth, TX 76107, USA, Tel: 817-735-2119; Fax: 817-735-2118; E-mail: lisa.hodge@unthsc.edu

Received January 30, 2012; Accepted February 05, 2012; Published February 09, 2012

Citation: Hodge LM (2012) Decongestive Physiotherapy for the Treatment of Lymphedema. J Blood Lymph 2:e107. doi:10.4172/2165-7831.1000e107

Copyright: @ 2012 Hodge LM. This is an open-access article distributed under the terms of the Creative Commons Attribution License, which permits unrestricted use, distribution, and reproduction in any medium, provided the original author and source are credited. 